\title{
The normative foundations of climate legislation
}

\section{Fergus Green}

[This is a pre-publication version of chapter 5 (pp. 85-107) of A. Averchenkova, S Fankhauser and M. Nachmany (eds.), 2017, Trends in Climate Change Legislation, Cheltenham: Edward Elgar.]

\subsection{INTRODUCTION}

Legislation, including on climate change, is inherently normative. It prescribes, permits and prohibits conduct, and it defines and allocates society's resources. Laws are necessarily both grounded in, and expressive of, values and ideals. Some of these 'normative foundations' may be ethical or political-philosophical, others embody international law, others still may be social, cultural or religious. Some may be widely shared across the globe, others particular to a jurisdiction.

In this chapter I am concerned with the ethical, political-philosophical and international-legal normative foundations of climate change legislation. Specifically: what have been the most prominent normative frameworks for responding to climate change proposed by scholars and practitioners to date? To what extent have they influenced domestic legislation and policy? What are their strengths and weaknesses? And what are the frontiers of normative change?

The chapter is structured as follows. Section 5.2 frames the ultimate normative problem of climate change in terms of the (re)distribution of human well-being and briefly introduces the three traditions of western normative philosophical thought that are most relevant to addressing it. Two of those traditions - liberal egalitarianism and utilitarianism - have informed the normative frameworks that have to date dominated normative theorizing about collective responses to climate change: climate justice and economic efficiency, respectively. These are introduced, along with key criticisms of each, in section 5.3. Section 5.4 introduces international climate law - a separate normative foundation - and identifies linkages between it and the political-philosophical (climate justice and economic efficiency) frameworks. Section 5.5 outlines three nascent 'movements' at the frontiers of climate policy and politics with which legislators will increasingly be called upon to engage: 'anti-fossil fuel' initiatives; 'green transformations'; and 'transitional fairness'/'just transition' claims. It explores the attendant legislative agendas of each and explains how these manifest a broadening of the normative foundations of climate legislation relative to the historically dominant climate justice and economic efficiency frameworks.

\subsection{WELL-BEING AND ITS DISTRIBUTION IN THE MAJOR PHILOSOPHICAL TRADITIONS}

\subsubsection{Climate Change and Human Well-being}

Any normative foundation for climate legislation must be rooted in an understanding of the values at stake. We do not value climate stability for its own sake. Rather, we seek to mitigate (and adapt to) climate change because it threatens more fundamental values (see Kolstad et al., 2014, pp. 220-23). One such value is human wellbeing. ${ }^{1}$ There are differing conceptions of well-being and correspondingly different ways of measuring it (ibid., 
p. 228). Nonetheless, there is a broad consensus that climate change poses a serious threat to the well-being of large numbers of humans. ${ }^{2}$

However, philosophers disagree about what should be done to mitigate the effects of climate change on human well-being, and why. Much of this disagreement stems from the reality that measures taken to mitigate climate change also affect the distribution of human well-being, quite apart from any reductions in climate change impacts. For example, renewable energy feed-in-tariffs may create new jobs, spur innovation and raise profits in the renewable energy sector while diminishing each of these in the fossil fuel energy sector.

Each of the three broad traditions of philosophical thought introduced below embodies a very different conception of well-being and how it ought to be (re)distributed among members of a political community.

\subsubsection{The Main Traditions of Political-philosophical Thought Relevant to Climate Change}

\section{(i) Liberal egalitarianism}

The dominant paradigm of contemporary western political philosophy is liberal egalitarianism, which is concerned with the social, economic and political relations that ought, as a matter of justice, to apply among persons considered as 'free and equal'. Theories of justice within this tradition typically specify principles concerning the allocation of (moral) rights and corresponding duties within a political community. Such rights are commonly theorized as intermediate concepts that protect the most weighty interests that all persons have as human beings - many of which (health, shelter, free expression and so on) pertain to well-being (c.f. Raz 1988, p. 181). ${ }^{3}$ Liberal egalitarian theories of justice thus seek to "identify "moral thresholds" below which people should not fall' in the interests of ensuring that all enjoy a minimum standard of well-being (Caney, 2010, p. 72).

The climate justice theories discussed below in section 5.3.1 follow the liberal egalitarian tradition.

\section{(ii) Utilitarianism}

Whereas liberal egalitarians seek to ensure a minimum threshold of well-being for each individual person, utilitarians seek to maximize the aggregate sum of expected well-being (a.k.a. 'utility') in a society. More relevantly for governments, 'rule utilitarians' seek to specify rules that would tend to maximize aggregate wellbeing.

Utilitarian concerns underpin the neoclassical economic approach to climate change via the intermediate concept of 'efficiency', which is contingently related to well-being conceived as 'preference satisfaction', as we shall see in section 5.3.2.

\section{(iii) Virtue ethics and republicanism: ancient and contemporary versions}

Whereas utilitarianism and justice-based approaches begin with the question, 'how should one act?', virtuebased approaches start from the question, 'what kind of person should one be?' This question is fundamentally related to the nature and purpose of 'the good life'. Ethical theorizing about the good life and the virtues stretches back to ancient times and remains a fertile field of ethical and political thought. Contemporary virtue theorists, for example, have much to say about human behaviour towards the natural environment that is relevant to climate change (see, for example, Cafaro and Sandler, 2005).

Recognizing that a society's civic institutions and political culture shape the kinds of persons who inhabit that society, some political theories emphasize 'civic virtue' - most notably 'republican' political theory, which is another rich tradition of political thought that has ancient roots and modern variants (see Pettit, 2013). 
I will suggest in section 5.5 that virtue-based approaches implicitly underpin some recent initiatives at the frontier of climate change politics and policy, such as anti-fossil fuel initiatives and visions of green transformation.

\subsection{THE HISTORICALLY DOMINANT NORMATIVE FRAMEWORKS FOR RESPONDING TO CLIMATE CHANGE: CLIMATE JUSTICE AND ECONOMIC EFFICIENCY}

\subsubsection{Climate Justice: Protecting Rights and Allocating Duties}

Climate justice scholars typically follow the liberal egalitarian tradition, considering how we ought to respond collectively to climate change by allocating duties to protect rights. To establish a theory of climate justice, proponents must (at least): specify the relevant human interests at stake; justify the protection of those interests by rights; explain who bears the corresponding duties to respect, protect and/or fulfil those rights; and justify that allocation of duties. Climate change poses considerable challenges with respect to each of these matters. Some approaches focus more on rights, others more on duties.

Starting with rights-focused approaches, philosophers have given varying accounts of the relevant human interests to be protected in the context of climate change (Bell, 2013). One account invokes a 'new' human right to a 'stable climate' (Vanderheiden, 2008), which can be derived from the human right to an 'adequate environment' (Nickel, 1993). The proposed right to a stable climate has been criticized on the grounds that it lacks determinacy (its content is difficult to specify) and is unnecessary because it is reducible to 'old' human rights such as rights to life, health and subsistence (Bell, 2013, pp. 163-5). An, alternative, more common, and arguably more intuitive approach focuses on the threat posed by climate change to this latter set of 'old' rights (Caney, 2010). ${ }^{4}$

In principle, the imperative to avoid harms or rights violations can inform the specification of climate change mitigation objectives, such as warming limits and carbon budgets. However, rights-focused approaches to climate justice face numerous problems. One problem lies in specifying the minimum package of rights to which all persons are entitled, since what counts as a minimally decent standard of well-being, and the rights deemed necessary to secure it, can be specified more or less generously. A further problem lies in deriving a climate objective from such a specification, given the many uncertainties and potential interventions in the causal chain between stocks of greenhouse gases (GHGs), degrees of warming, climate hazards and impacts on persons' well-being.

A further challenge for rights-based approaches is that they require a complementary account of who owes the duties to protect the rights, which in practice typically amounts to duties to limit or reduce GHG emissions. Some worry that rights proposed in the climate context imply excessively demanding burdens on duty bearers (Bell, 2013, pp. 164, 166-7). ${ }^{5}$ Others advocate allocating duties in the manner most likely to be efficacious in achieving the desired climate objective - for example, allocating duties in ways that appeal to the self-interest of politically powerful states (compare Broome, 2010, 2012, pp. 43-8; Caney, 2014; Posner and Weisbach, 2010). The latter set of proposals can be criticized on the ground that they entail an inequitable allocation of duties. 
Duty-focused approaches, on the other hand, take a given climate objective as their starting point and focus on the equitable global distribution of duties - often erroneously ${ }^{6}$ (and politically unhelpfully) labelled 'burdens' - to limit or reduce emissions. This involves the specification of normative principles for distributing a valuable but scarce common resource (typically defined as the absorptive capacity of the atmosphere or similar), of which there are various possibilities.

According to the 'polluter pays' principle, those who cause climate change owe the duties (which usually means that historic emissions are an important determinant of present and future emissions reduction duties). According to the 'beneficiary pays' principle, those who have benefited from GHG-emitting activities (as in the current citizens of states that are large historical emitters) owe the duties. 'Capacity to pay' implies that the wealthiest should bear the duties. 'Grandfathering' allocates emissions entitlements in proportion to current emissions, implying stronger emissions reduction duties for agents whose emissions are currently relatively low.

Proposed duty-allocation principles also differ along numerous other dimensions, such as: whether individual persons (including corporate persons) or states should bear the duties; the extent to which past emissions affect future obligations; and the extent to which background injustices or inequalities are taken into account in the distribution of duties. The different approaches all have their benefits and drawbacks (for a good overview see Roser and Seidel, 2017, pt. III).

In general, duty-focused approaches face the inverse challenges to rights-focused approaches. First, they must justify the objective on the basis of which duties are to be allocated in the first place. For example, what is the size of the 'carbon budget' to be divided? This leads us back to the question of rights, discussed above. Second, duty-focused approaches, by emphasizing equitable allocation of duties, may end up compromising the achievement of the ultimate objective because the most theoretically equitable allocation of duties may not be the most politically efficacious allocation (Caney, 2014).

Finally, utilitarians provide a general criticism of climate justice theories: by focusing on the protection of rights - which, recall, would guarantee a minimum threshold of well-being for all persons - such approaches fail to maximize aggregate well-being in the response to climate change. This charge highlights how justicebased approaches provide an inadequate framework for comparing the effects on well-being of alternative responses to climate change (including the effects of mitigation measures, adaptation measures and residual climate impacts) across diversely situated agents (Dietz, 2011, pp. 302-3).

Climate justice considerations appear to have had little direct influence on domestic climate legislation (Brown and Taylor, 2014). However, they have probably had some influence on the content of international climate law and thereby indirectly influenced domestic legislation (see section 5.4, below).

\subsubsection{Neoclassical Economics: Maximizing Efficiency}

Neoclassical economists evaluate and prescribe climate mitigation responses using an efficiency framework, which is (contingently) connected to the utilitarian tradition. The focus here is on the most widely used conception of efficiency, known technically as 'Kaldor-Hicks efficiency'. ${ }^{7}$ A proposed policy is considered efficiency-enhancing if, assuming the ability to make costless, ex post financial transfers, it would be possible for the winners from the policy to fully compensate the losers and still leave a residual economic benefit (that is, still leave at least one person better off). This is colloquially seen as a way of maximizing society's aggregate economic resources and hence maximizing society's economic capacity to achieve well-being, taking the 
existing distribution of resources as a given. Here, 'better off' and 'worse off' are measured in monetary terms: a person's 'willingness to pay' (WTP) to have a desired good or service, or not to have an undesired one, is taken to indicate the intensity of their preference. ${ }^{8}$ Such monetary values are used as crude proxies for wellbeing, where well-being is defined as 'the extent to which a person's preferences are satisfied'.

The potential to increase efficiency through policy intervention arises from the presence of 'market failure': roughly, a situation where the market fails to achieve a non-wasteful allocation of resources given an initial distribution. A common market failure is an externality: a situation in which the production or consumption of one party affects the well-being of a third party and yet the third party does not receive or pay a market price for that effect. The emission of GHGs by present people affects the well-being of other (present and future) people. Yet those who emit GHGs do not pay or receive a market price in respect of those effects, ${ }^{9}$ making emissions an externality - arguably the biggest market failure the world has ever seen (Stern, 2007). A commonly proposed economic policy solution is therefore to 'internalize' the cost of GHG emissions by enacting laws that generate a market price for those emissions.

But how much should emissions be reduced, and what policies should be implemented to achieve that goal? Neoclassical economists typically use cost-benefit analysis (CBA), based on WTP estimates, as a way of evaluating the net-benefits of a policy, ideally comparing the net-benefits of various alternative policies. Netbenefits are calculated by determining the aggregate costs of a climate policy (costs to losers plus policy implementation costs) and subtracting these from the aggregate benefits (usually limited to the avoided climate impacts enjoyed by the 'winners'). In the most ambitious CBA exercises, economists have sought to model the aggregate, long-term, global costs of achieving different temperature goals (the 'costs of action') and compared these with the avoided, long-term, global climate impacts associated with those temperature goals (the 'benefits of action', a.k.a the 'costs of inaction') (see, for example, Stern, 2007).

Economists' standard policy recommendation is to force polluters to pay a carbon price at the point at which the social marginal costs from GHG emissions (the climate damages) equal the social marginal benefits from the polluting activity. Economists tend to prefer explicit carbon prices in the form of a carbon tax or a carbon cap-and-trade scheme, as these are seen to be more efficient policy instruments than alternatives when tested using simple economic models (Goulder and Parry, 2008, pp. 155-9).

The main normative strength of the economic approach, it has been argued, is 'the formal framework through which it is able to compare human well-being across time, space, and states of nature, under alternative courses of action' (Dietz, 2011, p. 305).

As a normative foundation for climate legislation, the efficiency framework and its conclusions are vulnerable to numerous critiques. One kind of critique identifies factors affecting efficiency of which standard efficiency analyses fail to take account, resulting in inaccurate modelling and thus flawed policy prescriptions. Examples of the important phenomena that are typically ignored or poorly represented in standard models include:

- $\quad$ Other, non-GHG negative externalities caused by GHG-emitting processes (for example: local air, water and soil pollution or poor governance practices and human rights abuses by fossil fuel companies) (Parry et al., 2014; Smith, 2013).

- Other 'imperfections' in targeted markets (for example, the energy sector is characterized by a mixture of public and private ownership, layers of complex regulation, imperfect competition, information 
asymmetry, knowledge spillovers, path dependency and 'lock-in' effects) (Bruckner et al., 2014, sections 7.9 and 7.10).

- Administration and transaction costs (for example, the costs associated with the monitoring, reporting and verification (MRV) of GHG emissions. In the case of carbon pricing, MRV must be done at facility/installation level, encompassing hundreds or even thousands of installations in some countries) (Helm, 2005, p. 212).

- Dynamic effects of climate policies (for example, relating to technological innovation, path dependencies and strategic responses of resource owners) (Aghion et al., 2014; Grubb et al., 2014; Sinn, 2012; Stern, 2015).

- Political constraints, especially those affecting carbon pricing (Jenkins, 2014; Jenkins and Karplus, 2017).

- Extreme normative and empirical difficulties in calculating the efficiency costs of climate impacts/'the' social cost of carbon (Stern, 2013).

A second kind of critique can be levelled at the efficiency framework itself, on the ground that efficiency-maximizing policies are not necessarily - indeed, are unlikely to be - well-being maximizing, especially in the climate context (for general reasons for this, see Hausman and McPherson, 2006, p. 149; for applications of this critique to climate policy, see Goulder and Parry, 2008, pp. 165-6; Kolstad et al., 2014, p. 228). It is for these reasons that efficiency-maximizing policies are merely contingently utilitarian. ${ }^{10}$

A third kind of critique targets the aggregative characteristic of utilitarianism. Even climate policy packages that do maximize aggregate well-being can leave some, perhaps many, individuals worse off. While this is not necessarily objectionable, it may be so if there are independent reasons for favouring particular distributive consequences; it arguably matters who is made worse off (and who is made better off). Liberal egalitarian critics, for example, charge that a utilitarian response would not guarantee a basic threshold of wellbeing for all persons or, more simply, would fail to protect basic rights. On the other hand, one might think that it is morally acceptable for certain emitters to be made worse off as a result of climate policy - fossil fuel companies and their shareholders, perhaps. In any case, questions about the 'legitimacy' or 'deservingness' of claims by various agents for 'compensation' or 'transitional assistance' (which can be understood as claims to be not left worse off by the climate policy) are becoming increasingly prevalent, and are discussed below in section 5.5.3.

A fourth kind of criticism targets the 'informational basis' of utilitarianism, namely 'utility', or wellbeing conceived as the satisfaction of preferences for consuming goods and services. The purported strength of the economic framework - it comprehensively compares all possible well-being effects of alternative climate change responses - is purchased with the use of an implausibly narrow conception of well-being (Dietz, 2011, pp. 300-302). Reducing everything that matters in our response to climate change to 'the aggregate satisfaction of preferences' is to ignore or collapse too much that is distinctively valuable into a single informational unit of analysis.

The efficiency framework has exerted a significant influence on national climate policy and legislation in at least four ways. First, global CBA - most prominently the 2007 Stern Review of the Economics of Climate Change (Stern, 2007) - has informed emissions objectives that are debated by governments in the context of 
setting international and domestic mitigation targets. Second, standard economic policy prescriptions regarding the correction of the GHG externality through carbon pricing have found their way into international agreements, most notably as inspirations for the Kyoto Protocol's 'flexibility mechanisms' (emissions trading programmes of various kinds). They have also influenced the design of many such instruments at the domestic level (see World Bank, 2016). Third, efficiency considerations have influenced the design of domestic climate policies other than carbon pricing, including energy efficiency standards, renewable energy support policies, forest carbon sink enhancement policies and others. Fourth, CBA and cost-effectiveness analysis are firmly entrenched policy analysis techniques in many government departments that evaluate climate policy proposals.

\subsection{INTERNATIONAL LAW AS A NORMATIVE FOUNDATION FOR DOMESTIC CLIMATE LEGISLATION}

The climate justice and economic efficiency frameworks provide political-philosophical reasons for specific courses of climate action, including domestic legislation. These reasons can in principle apply to policies at the global or national levels. International climate change law constitutes a separate normative foundation. It provides legal reasons for specific courses of climate action, including domestic legislation, by states. Various fields of public international law are relevant to climate change, including international environmental, trade and human rights law. But the primary source of international climate law is the corpus of international climate change treaties, the most directly relevant of which are the United Nations Framework Convention on Climate Change (UNFCCC), the Paris Agreement and (albeit to a lesser extent now) the Kyoto Protocol.

While these treaties provide a freestanding normative (legal) foundation for domestic legislation, their content has been informed by the political-philosophical ideals discussed in the previous sections (Okereke, 2010). Most notably:

- The treaties contain objectives specified in terms of various 'thresholds' of temperature increase $\left(2^{\circ} \mathrm{C}\right.$, $1.5^{\circ} \mathrm{C}$ ) beyond which climate change is deemed unacceptably dangerous for large numbers of persons. These could be seen as a heuristic for a (rights-focused) justice-based concern to secure conditions for minimally acceptable standards of well-being for most persons (Dietz, 2011, p. 303). One could perhaps also see them as rough guides to well-being-maximizing levels of warming versus required mitigation effort (though economists differ considerably on this point: Dietz, 2011, p. 297).

- Principles such as 'equity' and 'common but differentiated responsibilities and respective capabilities' - and the specific 'burden-sharing' rules and target allocations of the Kyoto Protocol - can be seen as manifestations of equitable duty-allocation principles.

- The emphasis throughout the treaties on market-based mechanisms, and especially the Kyoto Protocol's 'flexibility mechanisms', reflect normative economic ideas about efficiency.

Nonetheless, due to the mediation of political factors in the process of treaty negotiation, the possible links between international climate law and the principles developed in the theoretical philosophy and economics literature should not be overstated (Okereke, 2010, pp. 466-8).

In any case, the contents of in-force climate treaties exert normative influence on states because they are, formally speaking, legally binding on the parties that have ratified them. However, the legal and practical consequences of this formal 'bindingness' depend on the specific, substantive content of the treaty: a particular 
clause of a treaty may be, in a different sense, 'more or less binding' on a party depending on various factors (Stavins et al., 2014, p. 24; Werksman, 2010).

International climate law has no doubt had some influence on domestic legislation. International climate law objectives, principles and rules have been formally invoked as normative foundations for domestic climate legislation in some countries. Examples include the preambular paragraphs of the EU Emissions Trading Directive, ${ }^{11}$ the EU's 2020 Climate and Energy Package, ${ }^{12}$ and the Explanatory Notes to the UK's Climate Change Act 2008, ${ }^{13}$ among others.

Arguably, however, international climate law has had very little influence on the detailed content of domestic climate legislation. Many of the objectives, principles and rules contained in the climate treaties are vague and their meaning remains essentially contested (Mayer, 2015, pp. 371-2; Okereke, 2010, p. 469). This is no coincidence: in multilateral negotiations, diplomatic agreement among countries with conflicting interests is obtained through such 'constructive ambiguity'; vagueness is often the price of agreement (Rajamani, 2009, p. 825). ${ }^{14}$ The result is that international climate law norms admit of a wide range of interpretive possibilities, providing very little in the way of normative guidance to domestic legislators (Mayer, 2015, p. 375; Okereke, 2010, p. 469; Werksman, 2010, pp. 674-5). This is exemplified by the way in which governments have invoked principles such as 'equity' and 'common but differentiated responsibilities' in diverse, typically self-serving and culturally relative ways (Brown and Taylor, 2014; Mayer, 2015, pp. 371-5). Consider, for example, the contrary ethical narratives invoked by different state groupings in the context of international climate negotiations (Mayer, 2015, pp. 372-5) and by individual states to justify the fairness of their national contributions to the Paris Agreement (see UNFCCC Secretariat 2016, paras. 169-79).

Stronger normative guidance has undoubtedly been provided by the more specific rules of the international climate regime, such as the Kyoto Protocol's emissions targets and flexibility mechanisms. These clearly influenced the design of the EU Emissions Trading Scheme (ETS), for example. However, determining the achievement of de jure GHG mitigation targets is a phenomenally complex socio-technical enterprise involving myriad MRV rules and layers of public and private governance practices through which 'facts on the ground' are translated into quantifiable, fungible and tradeable emissions units (Kuch, 2015; MacKenzie, 2009; van Zeben, 2014). Numerous studies have demonstrated how a combination of 'generous' accounting provisions relating to land-use and forestry, tradeable 'hot air' credits, and tradeable project-based credits of dubious environmental integrity ultimately gave states wide interpretive latitude in achieving their Kyoto targets (Kollmuss et al., 2015; Kuch, 2015; Schneider and Kollmuss, 2015; Shishlov et al., 2016; Stavins et al., 2014, pp. 1041-47).

In any case, the primacy of (superficially) strong 'rules' in international climate law has waned. The successful negotiation of the Paris Agreement was achievable, in part, precisely because it did away with a system of collectively agreed, legally binding national targets and associated systems of compliance-oriented international accounting. ${ }^{15}$ Indeed, the mitigation aspects of the Paris Agreement were explicitly crafted with the dual intention of being more political-facilitative than legal-punitive in character, and of giving states wide flexibility as to their choice of domestic objectives and the policies and measures by which to achieve them (Christoff, 2016; Falkner, 2016; Hale, 2016). ${ }^{16}$ The strongest normative influence relating to the Paris Agreement thus comes from countries' own 'Nationally Determined Contributions', which are normative 
expressions of intent that are expected to provide guidance for domestic climate legislation (Bodansky, 2016, p. 304). It remains to be seen how effective these commitment devices will be.

\subsection{THE FRONTIERS OF CLIMATE POLICY AND POLITICS: ALTERNATIVE LEGISLATIVE AGENDAS AND THEIR NORMATIVE FOUNDATIONS}

Recent developments at the frontiers of climate policy and politics reflect a broadening of the politicalphilosophical foundational approaches to climate change. Three such 'movements' are discussed in this section: anti-fossil fuel initiatives; green transformations; and transitional fairness/just transition claims (for more detailed discussion of these, see Green, 2017, forthcoming). These movements have emerged partly in response to mounting frustration at the lack of political progress in tackling climate change in the 1990s and 2000s (see Green, forthcoming; Hale, 2016, p. 15).

\subsubsection{Anti-fossil Fuel Initiatives}

Recently, climate activists have turned their attention towards fossil fuels, with campaigns targeting new fossil fuel infrastructure and urging institutional investors to divest from fossil fuel stocks (Klein, 2014; McKibben, 2012). Scholars of climate policy have also begun to focus on fossil fuels (see, for example, the forthcoming special issue of Climatic Change on fossil fuel supply and climate policy, expected 2018).

The legislative agenda associated with this movement includes: quantity-based policies such as moratoria and bans on new fossil fuel production, more restrictive fossil fuel exploration and productionlicensing regimes, regulated phase-outs of fossil fuel production, and tradeable production quotas; and pricebased policies such as the reduction of fossil fuel subsidies and the imposition of fossil fuel production taxes (for a useful typology see Lazarus et al., 2015, pp. 7-9). This agenda also implicates changes to administrative processes and decision making, including: ${ }^{17}$ reducing discretionary fiscal allocations to fossil fuel producers; requiring state investment funds to divest from fossil fuel holdings; stricter policies towards project approvals and licensing conditions; changes to GHG accounting rules (for example, to take account of embodied carbon and lock-in effects); more comprehensive CBA and environmental impact assessments of proposed fossil fuel projects (to take account of a wider range of adverse impacts); and wider stakeholder engagement in project approval, siting and licensing processes (to facilitate greater community input).

This new frontier of fossil fuel activism, scholarship and policy/legislative reform is being developed largely without reference to any explicit normative foundations in philosophy or international law (though this is beginning to change: see Green, forthcoming; Jamieson, 2017; Moss, 2016). The philosophical foundations can, however, be inferred from the associated practices. Anti-fossil fuel initiatives clearly share some normative foundations with the dominant frameworks discussed in section 5.3 insofar as they are partly motivated by concerns about the impacts of climate change on human well-being. But their normative foundations are, implicitly, broader in at least two respects.

First, these initiatives are typically concerned with the full range of adverse impacts caused by fossil fuels, including not only climate change but also the local environmental, health, social, economic and political/governance effects of fossil fuel production, transportation and downstream combustion. Accordingly, they track a wider array of adverse impacts on human well-being (and a wider array of rights violations and market failures). 
Second, these initiatives typically involve deliberate attempts to single out specific actors and industries - especially fossil fuel companies - for a range of 'vices'. As such, they mark a qualitative (not merely quantitative) distinction in the moral character of those agents who are disproportionately responsible for causing or contributing to GHG emissions and other harmful impacts. The activist core of the anti-fossil fuel movement also harnesses an affective dimension to this moral isolation of these allegedly vicious agents, seeking to publicly shame both fossil fuel companies themselves and other powerful agents that support them, such as governments and institutional investors (Ayling and Gunningham, 2015; Green, forthcoming). These initiatives thus implicitly rely partly on a virtue-ethical normative foundation (see section 5.2.2 (iii)) in a way that the dominant frameworks do not.

\subsubsection{Green Transformations}

Anti-fossil fuel movements reflect a 'negative' vision; a vision of what needs to be stopped, reversed and phased out. But our response to climate change also requires a positive vision: a compelling narrative about the good life in a decarbonized/ing world (Lane, 2011, ch. 1; Perez, 2013). Such visions are necessary to guide the direction of policy, legislation and resource allocation over long-time frames and multiple issue-areas. They can also help to communicate such an agenda publicly in a way that captures people's imagination and mobilizes support - something that mainstream appeals to abstract notions such as efficiency and climate justice have manifestly failed to do.

In recent years the frontiers of activism and scholarship have witnessed a flowering of visions of 'green transformation', complemented with an increasingly sophisticated theoretical and empirical tool kit (Scoones et al., 2015). Such visions are diverse in their diagnosis of what needs to be transformed and in their prescriptions of how such transformation should occur. They emphasize different agents (states, citizens, firms, entrepreneurs), different structures (state agencies, social movements, markets, innovation systems) and, ultimately, different 'pathways' to transformative change (ibid.). This plurality makes it difficult to identify a single, associated legislative agenda. Nonetheless, these visions share an understanding that the response to climate change must be fundamental, comprehensive, transformative and sustained over the long term. These characteristics in turn suggest that legislators will need to attend to certain features of the legislative response.

One such feature is the importance of institutions - not so much as ends in themselves (as per the 'optimal carbon price'), but rather as significant interventions into complex social systems that can create positive feedback effects in the desired direction of change, which accumulate over time (González-Ricoy and Gosseries, 2016; Grubb et al., 2014; Lockwood, 2015). Another is the enhanced role of the state in the (green) directing and shaping of economic activity (Bowen and Hepburn, 2015), including via: the direct provision, financing and facilitating of clean technologies and processes (Aghion et al., 2014; Grubb et al., 2014; Mazzucato, 2015; Perez, 2013; Stern, 2015); green infrastructure (Zenghelis, 2014); and green industrial policy (Rodrik, 2015). Another still is the integration of climate mitigation concerns and analysis horizontally across traditional policy areas and portfolios (Compston and Bailey, 2013) and vertically between different levels of government, which is often especially challenging in federal systems (Brown, 2012).

These features of green transformations imply a set of normative foundations that goes beyond, and challenges, the paradigmatically 'modern' liberal egalitarian and utilitarian traditions. In the modern mindset, the 'preferences' of agents and the constituents of well-being are typically taken as fixed and given. Modern political philosophy is largely about formulating fair distributive institutions that operate within these 
constraints while being 'neutral' between people's competing conceptions of the 'good' life. Visions of green transformation instead bring to the fore a more characteristically ancient set of questions about the nature of the good life, the role of government in promoting it, and about large-scale shifts in the social ethos within which beliefs, values and 'preferences' are formed (Lane, 2011). This normative project, in its application to green transformations, is very much a work in progress. But insights can be gleaned from contemporary philosophers who have brought ancient and republican philosophical ideas and methods to bear on the question of climate change (Lamb and Lane, 2016; Lane, 2011), and from the broader literature on green political theory in which questions of value transformation have been prominent (Jamieson, 2007, 2014, 2017; and for discussion and further references see Lane 2016, pp. 114-15).

\subsubsection{Transitional Fairness and 'Just Transition' Claims}

The third frontier of climate policy and politics can be seen as the hinge between the 'negative' vision of fossil fuel decarbonization and the 'positive' vision(s) of green transformation. It concerns the question: what to do about those who are entangled in the fossil fuel economy and in other carbon-intensive sectors that need to decline? In particular, we can think of this question as applying to: workers in carbon-intensive industries; owners of carbon-intensive and energy-intensive assets; and strongly indirectly affected persons or groups (such as communities in coal-mining regions). Asset owners can further be divided into owners of carbon-intensive commercial assets (such as shares in a coal company; capital goods) and owners of carbon-intensive household assets (for example, combustion engine passenger vehicles; energy-inefficient homes).

The answer to the question has both a normative dimension (in that it is a matter of justice or fairness) and a prudential/political dimension (since potential losers tend disproportionately to influence the design and legislative fate of climate policy proposals) (Green, 2017; Trebilcock, 2014). Yet, in seeking normatively satisfying and politically pragmatic answers, most existing normative theories serve us poorly, tending to offer 'all' ('fully compensate all the losers') or 'nothing' ('let losses lie where they fall') responses to transitional questions that really require nuance and fine distinctions (Green 2017; Shaviro, 2000, pp. 3-4, 17-19). ${ }^{18}$

Normative theorizing about 'transitions' ultimately raises questions about the role of stability versus change in the good life, about citizens' civic duties in the context of major legal reforms, and about the role of institutions in facilitating transitions. As such, theorizing about transitional justice repays engagement with the virtue-oriented traditions of ethical and political thought discussed in section 5.2.2 (iii). Additionally, attending to historical examples of similar kinds of large-scale transitions can provide useful normative and political insights that may be applicable to contemporary debates (Jamieson, 2017; Lane, 2016, p. 113; Rosemberg, 2010, p. 150).

In any case, as climate policy and legislation become increasingly stringent, the putative 'losers' from such changes can be expected to assert ever stronger political claims for transitional relief and assistance. One prominent class of transitional claimants has been emissions-intensive business corporations seeking compensation for lost asset value (see, for example, Menezes et al., 2009). Another development has been the loudening calls from parts of the organized labour movement, echoed by other civil society actors, for 'just transition' policies to accompany climate change mitigation. ${ }^{19}$ 'Just transition' can broadly be defined as a framework within which the labour movement seeks to 'maximize benefits and minimize hardships for workers and their communities' in the transformation to a low-carbon and climate-resilient economy (Rosemberg, 2010, p. 141). Just transition ideas are being increasingly taken seriously by mainstream political parties and 
legislatures. For example, the Australian Labor Party and Australian Greens both included a just transition strategy in their 2016 federal election manifestos. Additionally, the Australian Senate Environment and Communications Legislation Committee's (2017) Final Report into the Retirement of Coal Fired Power Stations includes recommendations concerning just transition from senators representing all major political parties (at 71, $76,80)$.

Whatever the normative merits of particular transitional claims, legislators face a difficult task when it comes to translating them into a principled programme of transitional support. Challenges include (Green, 2017):

- $\quad$ specifying the purpose(s) of just transition policies (backward-looking compensation for loss, forwardlooking 'structural adjustment' to prevailing market conditions, or more holistic support for the maintenance of valued communities, lifestyles and forms of work);

- $\quad$ articulating the normative justification for the provision of transitional assistance (which has precedential implications for other transitions);

- defining and justifying the scope of eligible claimants (differentiating between workers, asset owners and indirectly affected persons and groups) and including groups who are typically less represented in the political process;

- determining the kind and duration of transitional relief or assistance to be granted (including the balance between individual payments, individual in-kind support, and investment in public goods such as community infrastructure);

- distinguishing transitional assistance (and its normative justification) from existing categories of social expenditure (and their normative justifications).

These complexities illustrate some of the difficult trade-offs implied in just transition strategies and reinforce the urgent need for thoughtful applied normative-theoretical, economic and political analysis in this area.

\subsection{CONCLUSION}

This chapter has introduced the main normative foundations of climate legislation: the liberal egalitarianinspired climate justice framework; the utilitarian-inspired economic efficiency framework; and international climate law. In doing so, it has sought to help practitioners interpret, navigate and critically evaluate the normative claims advanced by philosophers, economists, lawyers and other stakeholders in the course of debates over climate policy and legislation.

Though they each have their strengths and weaknesses, neither the climate justice nor the economic efficiency framework has proven usefully action-guiding for domestic climate legislators. Part of the problem lies in the fact that each framework invokes highly abstract, comprehensive, global, long-term, politically unconstrained normative ideals. It is therefore unsurprising that it has proven difficult to translate them into specific, partial, local, near-term, politically constrained legislation. While international climate treaties have borrowed from each of these (political-philosophical) frameworks, those treaties have also proved to be only very weakly action-guiding for domestic legislators. Perhaps some of the blame rests with legislators, but much of it arguably rests with the foundational theories and frameworks themselves. 
In different but overlapping ways, anti-fossil fuel, green transformation and just transition movements draw implicitly on a wider and richer set of normative concerns - especially those associated with the virtueethical tradition of philosophical thought. Much work from within this tradition remains to be done in establishing normative frameworks and principles that are sufficiently action-guiding to be useful to domestic climate legislators. But a promising agenda at the interface of philosophy, politics, economics and law is beginning to take shape. The resulting normative frameworks and principles are likely to be more fragmented and partial, concrete and messy, short term and local than the historically dominant frameworks. Yet, precisely for these reasons, they might prove much more useful to legislators in the crucial years to come.

\section{NOTES}

1. 'Well-being' is sometimes used interchangeably or synonymously with 'welfare', though often the latter connotes a narrower conception of well-being. To avoid confusion, I use well-being throughout this chapter.

2. Climate change also threatens non-human animals, other living things, the survival of species, and the integrity of many ecosystems.

Various non-anthropocentric theories of value attribute ultimate value to one or other of these phenomena (see Kolstad et al., 2014, p. 220). For reasons of space and simplicity, this chapter limits the discussion to anthropocentric theories, for which these other phenomena have merely 'instrumental' value.

3. Alternatively, rights can be justified intrinsically, either as 'natural rights', or by reference to the status of persons as autonomous agents worthy of respect, as with scholars in the Kantian tradition (see Bell, 2013, p. 161 and references there cited).

4. A third, very different approach, invokes a right to emit GHGs per se - either as a right to an equal per capita share of the absorptive capacity of the atmosphere, or a right to 'subsistence emissions'. However, this approach has been strongly criticized (see Bell, 2013, pp. $167-8)$.

5. Moreover, for such rights to be realized in practice, they must be codifiable in a legitimate formal structure, it must be feasible to claim the rights, and there must be a functioning enforcement mechanism in place (Brandstedt and Bergman, 2013).

6. I do not wish to suggest that no mitigation measures entail burdens, just that mitigation measures do not necessarily entail burdens. See Green (2015) for an elaboration of this argument.

7. A closely related concept is Pareto efficiency. A separate concept is cost-effectiveness. Space constraints preclude introduction of these concepts here. For an unrivalled, philosophically rigorous yet policy-oriented and accessible introduction, see Hausman and McPherson (2006).

8. See Mendelsohn and Olmstead (2009) for a discussion of how economists try to measure people's WTP; see Hausman and McPherson (2006, pp. 149-51) for critical analysis of such techniques.

9. Some readers may wonder why the possibility that polluters may 'receive' a payment is mentioned here. The simple reason is that neoclassical economic efficiency analysis does not presuppose that the 'polluter pays'. Ronald Coase's work (for example, Coase, 1960) established that, absent transaction costs, the incorporation of an externality into a market price yields the same efficiency result whichever party pays the price. Of course, the distributional result will depend on which party pays - polluter or society, in the climate case - and of course there are transaction costs in the real world (indeed, convincing economists to study the transaction costs was precisely Coase's goal).

10. Some economic analyses are genuinely utilitarian in that they convert the modelled aggregate monetary impacts of a course of climate action into an effect on aggregate well-being through the use of a 'representative' utility function (Dietz, 2011, p. 300). However, this kind of utilitarian analysis is more common in global economic analyses of climate responses than domestic policy analysis, and is in any case vulnerable to the 'third' and 'fourth' kinds of critiques discussed in section 5.3.2.

11. Directive 2003/87/EC of the European Parliament and of the Council of 13 October 2003 establishing a scheme for greenhouse gas emission allowance trading within the European Community and amending Council Directive 96/61/EC.

12. Decision No 406/2009/EC of the European Parliament and of the Council of 23 April 2009 on the effort of member states to reduce their greenhouse gas emissions to meet the EC's greenhouse gas emission reduction commitments up to 2020.

13. See http://www.legislation.gov.uk/ukpga/2008/27/notes/contents.

14. While this problem attends all multilateral agreements, it is especially pronounced in international climate change treaties.

15. The yet-to-be agreed MRV system for Nationally Determined Contributions (NDCs) is not geared towards compliance, since achievement of NDC targets is not mandatory under the agreement. Rather, it is geared towards 'transparency' of NDC outcomes, on the basis of which state-peer and civil society pressure can be exerted.

16. As I have argued elsewhere, this was a wise approach in light of international political realities (Green, 2014).

17. Some of these may also require legislative changes, depending on the jurisdiction.

18. For more thoughtful responses (though not responses I necessarily endorse), see: Shaviro (2000), invoking the efficiency framework; Bovens (2011) and Knight (2013), invoking 'grandfathering'; and Meyer and Sanklecha (2014), invoking 'legitimate expectations'.

19. The growing attention to 'just transition' is reflected in the successful lobbying by such groups for a reference to 'just transition' in the preamble to the Paris Agreement, the publication by the International Labour Organisation in 2015 of its 'Guidelines' concerning just transition, and the (probably related) explosion of reports and manifestos concerning just transition in the 2015-17 period (e.g. Kumar et al., 2016).

\section{REFERENCES}

Aghion, P., C. Hepburn, A.Teytelboym and D. Zenghelis (2014), Path Dependence, Innovation and the Economics of Climate Change, Centre for Climate Change Economics \& Policy and Grantham Research Institute on Climate Change \& The Environment, policy paper, accessed 14 July 2017 at http://2014.newclimateeconomy.report/wpcontent/uploads/2014/11/Path-dependence-and-econ-of-change.pdf. 
Ayling, J. and N. Gunningham (2015), 'Non-state governance and climate policy: the fossil fuel divestment movement', Climate Policy, 17(2), 131-49.

Bell, D. (2013), 'Climate change and human rights', Wiley Interdisciplinary Reviews: Climate Change, 4(3), 159-70.

Bodansky, D. (2016), ‘The Paris climate change agreement: a new hope?', The American Journal of International Law, 110(2), 288-319.

Bovens, L. (2011), 'A Lockean defense of grandfathering emission rights', in D.G. Arnold (ed.), The Ethics of Global Climate Change, Cambridge: Cambridge University Press, pp. 124-44.

Bowen, A. and C. Hepburn (2015), 'Green growth: an assessment', Oxford Review of Economic Policy, 30(3), 407-22.

Brandstedt, E. and A.-K. Bergman (2013), 'Climate rights: feasible or not?', Environmental Politics, 22(3), $394-409$.

Broome, J. (2010), 'The most important thing about climate change', in J. Boston, A. Bradstock and D. Eng (eds), Public Policy: Why Ethics Matters, Canberra: ANU E-Press, pp. 101-16.

Broome, J. (2012), Climate Matters: Ethics in a Warming World, London and New York: W. W. Norton \& Co.

Brown, D.A. and P. Taylor (2014), 'Introduction', in D.A. Brown and P. Taylor, Ethics and Climate Change: A Study of National Commitments, Gland, Switzerland: IUCN, xvii-xxx.

Brown, D.M. (2012), 'Comparative climate change policy and federalism: an overview', Review of Policy Research, 29(3), $322-33$.

Bruckner, T. et al. (2014), 'Energy systems', in O. Edenhofer et al. (eds), Climate Change 2014: Mitigation of Climate Change. Contribution of Working Group III to the Fifth Assessment Report of the Intergovernmental Panel on Climate Change, Cambridge: Cambridge University Press, pp. 511-98.

Cafaro, P. and R.D. Sandler (2005), Environmental Virtue Ethics, Lanham, MD: Rowman \& Littlefield.

Caney, S. (2010), 'Climate change, human rights and moral thresholds', in S. Humphreys (ed.), Human Rights and Climate Change, Cambridge: Cambridge University Press, pp. 69-90.

Caney, S. (2014), 'Two kinds of climate justice: avoiding harm and sharing burdens', Journal of Political Philosophy, 22(2), $125-49$.

Christoff, P. (2016), 'The promissory note: COP 21 and the Paris climate agreement', Environmental Politics, 25(5), 76587.

Coase, R.H. (1960), 'The problem of social cost', The Journal of Law and Economics, 3, 1-44.

Compston, H. and I. Bailey (2013), 'Climate policies and anti-climate policies', Open Journal of Political Science, 3(4), $146-57$.

Dietz, S. (2011), 'From efficiency to justice: utility as the informational basis of climate strategies, and some alternatives', In J.S. Dryzek, R.B. Norgaard and D. Schlosberg (eds), The Oxford Handbook of Climate Change and Society, Oxford: Oxford University Press, pp. 295-308.

Environment and Communications Legislation Committee (2017), Retirement of Coal Fired Power Stations: Final Report, Commonwealth of Australia, accessed 14 July 2017 at http://www.aph.gov.au/Parliamentary_Business/Committees/Senate/Environment_and_Communications/Coal_fired _power_stations/Final_Report.

Falkner, R. (2016), 'The Paris Agreement and the new logic of international climate politics', International Affairs, 92(5), $1107-25$.

González-Ricoy, I. and A. Gosseries, eds (2016), Institutions For Future Generations, Oxford: Oxford University Press.

Goulder, L.H. and I.W.H. Parry (2008), 'Instrument choice in environmental policy', Review of Environmental Economics and Policy, 2(2), 152-74.

Green, F. (2014), 'This Time Is Different': The Prospects for an Effective Climate Agreement in Paris 2015, Centre for Climate Change Economics \& Policy and Grantham Research Institute on Climate Change \& The Environment, policy paper, accessed 14 July 2017 at http://www.lse.ac.uk/GranthamInstitute/wp-content/uploads/2014/10/ThisTime-is-Different.pdf. 
Green, F. (2015), Nationally Self-Interested Climate Change Mitigation: A Unified Conceptual Framework, Centre for Climate Change Economics \& Policy Working Paper No. 224 and Grantham Research Institute on Climate Change \& The Environment Working Paper No. 199, accessed 14 July 2017 at http://www.lse.ac.uk/GranthamInstitute/wpcontent/uploads/2015/07/F_Green_Nationally_Self_Interested_Climate_Change_Mitigation.pdf.

Green, F. (2017), 'Transition policies for climate change mitigation: who, what, why and how', Working Paper, Centre for Climate Economics and Policy, Crawford School of Public Policy, Australian National University.

Green, F. (Forthcoming), 'Anti-fossil fuel norms', Climatic Change.

Grubb, M., J.-C. Hourcade and K. Neuhoff (2014), Planetary Economics: Energy, Climate Change and the Three Domains of Sustainable Development, London and New York: Routledge.

Hale, T. (2016), “'All hands on deck”: the Paris Agreement and nonstate climate action', Global Environmental Politics, 16(3), 12-22.

Hausman, D.M. and M.S. McPherson (2006), Economic Analysis, Moral Philosophy and Public Policy, 2nd edn, Cambridge, UK: Cambridge University Press.

Helm, D. (2005), 'Economic instruments and environmental policy', The Economic and Social Review, 36(3), 205-28. Jamieson, D. (2007), 'When utilitarians should be virtue theorists', Utilitas, 19(2), 160.

Jamieson, D. (2014), Reason in a Dark Time: Why the Struggle to Stop Climate Change Failed - and What It Means for Our Future, New York: Oxford University Press.

Jamieson, D. (2017), 'Slavery, carbon, and moral progress', Ethical Theory and Moral Practice, 20(1), 169-183.

Jenkins, J.D. (2014), 'Political economy constraints on carbon pricing policies: what are the implications for economic efficiency, environmental efficacy, and climate policy design?', Energy Policy, 69, 467-77.

Jenkins, J.D. and V.J. Karplus (2017), 'Carbon Pricing under Political Constraints', in D. Arent et al. (eds.), The Political Economy of Clean Energy Transitions, Oxford: Oxford University Press, pp. 39-59.

Klein, N. (2014), This Changes Everything: Capitalism vs the Climate, New York: Simon \& Schuster.

Knight, C. (2013), 'What is grandfathering?', Environmental Politics, 22(3), 410-27.

Kollmuss, A., L. Schneider and V. Zhezherin (2015), Has Joint Implementation Reduced GHG Emissions? Lessons Learned for the Design of Carbon Market Mechanisms, Stockholm Environment Institute Working Paper 2015-07, accessed 14 July 217 at https://www.sei-international.org/mediamanager/documents/Publications/Climate/SEI-WP-2015-07JI-lessons-for-carbon-mechs.pdf.

Kolstad, C. et al. (2014), 'Social, economic, and ethical concepts and methods', in O. Edenhofer et al., Climate Change 2014: Mitigation of Climate Change. Contribution of Working Group III to the Fifth Assessment Report of the Intergovernmental Panel on Climate Change, Cambridge: Cambridge University Press, pp. 207-82.

Kuch, D. (2015), The Rise and Fall of Carbon Emissions Trading, Basingstoke: Palgrave Macmillan.

Kumar, S., A. Americo and C. Billingham (2016), The New Social Contract: A Just Transition, Brussels: FEPS, accessed 14 July 2017 at http://www.feps-europe.eu/assets/edfdcaca-97a7-407c-b21c-4f2ca4f4b050/2016-10finalwebnewsocialcontractjusttransitionpdf.pdf.

Lamb, M. and M. Lane (2016), 'Aristotle on the ethics of communicating climate change', in C. Heyward and D. Roser (eds), Climate Justice in a Non-Ideal World, Oxford: Oxford University Press, pp. 229-54.

Lane, M. (2011), Eco-Republic: Ancient Thinking for a Green Age, Witney, Peter Lang Ltd.

Lane, M. (2016), 'Political theory on climate change', Annual Review of Political Science, 19(1), 107-23.

Lazarus, M., P. Erickson and K. Tempest (2015), Supply-Side Climate Policy: The Road Less Taken, Stockholm Environment Institute Working Paper 2015-13, accessed 14 July 2017 at http://www.seiinternational.org/mediamanager/documents/Publications/Climate/SEI-WP-2015-13-Supply-side-climate-policy.pdf.

Lockwood, M. (2015), 'The political dynamics of green transformations: feedback effects and institutional context', in I. Scoones, M. Leach and P. Newell (eds), The Politics of Green Transformations, Oxford: Routledge, pp. 86-101. 
MacKenzie, D. (2009), 'Making things the same: gases, emission rights and the politics of carbon markets', Accounting, Organizations and Society, 34(3-4), 440-55.

Mayer, B. (2015), 'Conceiving the rationale for international climate law', Climatic Change, 130(3), 371-82.

Mazzucato, M. (2015), 'The green entrepreneurial state', in I. Scoones, M. Leach and P. Newell, The Politics of Green Transformations, Oxford: Routledge, pp. 134-52.

McKibben, B. (2012), 'Global warming's terrifying new math', Rolling Stone, accessed 14 July 2017 at http://www.rollingstone.com/politics/news/global-warmings-terrifying-new-math-20120719.

Mendelsohn, R. and S. Olmstead (2009), 'The economic valuation of environmental amenities and disamenities: methods and applications', Annual Review of Environment and Resources, 34(1), 325-47.

Menezes, F., J. Quiggin and L. Wagner (2009), 'Grandfathering and greenhouse: the role of compensation and adjustment assistance in the introduction of a carbon emissions trading scheme for Australia', Economic Papers: A Journal of Applied Economics and Policy, 28(2), 82-92.

Meyer, L. and P. Sanklecha (2014), 'How legitimate expectations matter in climate justice', Politics, Philosophy \& Economics, 13(4), 369-93.

Moss, J. (2016), 'Mining, morality and the obligations of fossil fuel exporting countries', Australian Journal of Political Science, 51(3), 496-511.

Nickel, J.W. (1993), 'The human right to a safe environment: philosophical perspectives on its scope and justification', Yale Journal of International Law, 18(1), 281-95.

Okereke, C. (2010), 'Climate justice and the international regime', Wiley Interdisciplinary Reviews: Climate Change, 1(3), 462-74.

Parry, I., C. Veung and D. Heine (2014), 'How much carbon pricing is in countries' own interests? The critical role of cobenefits', IMF Working Paper WP/14/174.

Perez, C. (2013), 'Unleashing a golden age after the financial collapse: drawing lessons from history', Environmental Innovation and Societal Transitions, 6, 9-23.

Pettit, P. (2013), 'Two republican traditions', in A. Niederberger and P. Schink, Republican Democracy: Liberty, Law and Politics, Edinburgh: Edinburgh University Press, pp. 169-204.

Posner, E. and D. Weisbach (2010), Climate Change Justice, Princeton, N.J.: Princeton University Press.

Rajamani, L. (2009), "Addressing the "post-Kyoto" stress disorder: reflections on the emerging legal architecture of the climate regime', International and Comparative Law Quarterly, 58(4), 803.

Raz, J. (1988), The Morality of Freedom, Oxford: Clarendon Press.

Rodrik, D. (2015), 'Green industrial policy', Oxford Review of Economic Policy, 30(3), 469-91.

Rosemberg, A. (2010), 'Building a just transition', International Journal of Labour Research, 2(2), 125-62.

Roser, D. and C. Seidel (2017), Climate Justice: An Introduction, New York: Routledge.

Schneider, L. and A. Kollmuss (2015), 'Perverse effects of carbon markets on HFC-23 and SF6 abatement projects in Russia', Nature Climate Change, 5, 1061-3.

Scoones, I., P. Newell and M. Leach (2015), 'The politics of green transformations', in I. Scoones, M. Leach and P. Newell (eds), The Politics of Green Transformations, Oxford: Routledge, pp. 1-24.

Shaviro, D. (2000), When Rules Change: An Economic and Political Analysis of Transition Relief and Retroactivity, Chicago, Ill.: University of Chicago Press.

Shishlov, I., R. Morel and V. Bellassen (2016), 'Compliance of the parties to the Kyoto Protocol in the first commitment period', Climate Policy, 16(6), 768-82.

Sinn, H.-W. (2012), The Green Paradox: A Supply-Side Approach to Global Warming, Chicago: The MIT Press.

Smith, A. (2013), The Climate Bonus: Co-Benefits of Climate Policy, London: Earthscan. 
Stavins, R. et al. (2014), 'International cooperation: agreements \& instruments', in O. Edenhofer et al., Climate Change 2014: Mitigation of Climate Change. Contribution of Working Group III to the Fifth Assessment Report of the Intergovernmental Panel on Climate Change, Cambridge: Cambridge University Press, pp. 1001-82.

Stern, N. (2007), The Economics of Climate Change: The Stern Review, Cambridge: Cambridge University Press.

Stern, N. (2013), 'The structure of economic modeling of the potential impacts of climate change: grafting gross underestimation of risk onto already narrow science models', Journal of Economic Literature, 51(3), 838-59.

Stern, N. (2015), Why Are We Waiting? The Logic, Urgency, and Promise of Tackling Climate Change, London: The MIT Press.

Trebilcock, M.J. (2014), Dealing with Losers: The Political Economy of Policy Transitions, Oxford: Oxford University Press.

UNFCCC Secretariat (2016), 'Aggregate effect of the intended nationally determined contributions: an update', synthesis report by the secretariat, UN Doc FCCC/CP/2016/2.

Vanderheiden, S. (2008), Atmospheric Justice: A Political Theory of Climate Change, New York: Oxford University Press.

Werksman, J. (2010), 'Legal symmetry and legal differentiation under a future deal on climate', Climate Policy, 10(6), 67277.

World Bank (2016), State and Trends of Carbon Pricing, Washington, DC, accessed 14 July 2017 at https://openknowledge.worldbank.org/handle/10986/25160.

van Zeben, J. (2014), The Allocation of Regulatory Competence in the EU Emissions Trading Scheme, Cambridge: Cambridge University Press.

Zenghelis, D. (2014), 'In praise of a green stimulus', Wiley Interdisciplinary Reviews: Climate Change, 5(1), 7-14. 